\title{
Efficacy, Retention and Tolerability of Everolimus in Patients with Tuberous Sclerosis Complex: A Survey-Based Study on Patients' Perspectives
}

\author{
Laurent M. Willems $s^{1,2} \cdot$ Felix Rosenow ${ }^{1,2}$. Susanne Schubert-Bast ${ }^{1,2,3} \cdot$ Gerhard Kurlemann $^{4}$. \\ Johann Philipp Zöllner ${ }^{1,2}$. Thomas Bast ${ }^{5}$. Astrid Bertsche ${ }^{6}$. Ulrich Bettendorf ${ }^{7}$. Daniel Ebrahimi-Fakhari ${ }^{8}$. \\ Janina Grau ${ }^{1,2}$. Andreas Hahn ${ }^{9} \cdot$ Hans Hartmann ${ }^{10}$. Christoph Hertzberg ${ }^{11}$. Frauke Hornemann ${ }^{12} \cdot$ Ilka Immisch $^{13}$. \\ Julia Jacobs ${ }^{14,15} \cdot$ Karl Martin Klein ${ }^{1,2,16} \cdot$ Kerstin A. Klotz ${ }^{14,17}$. Gerhard Kluger ${ }^{18,19}$. Susanne Knake ${ }^{13}$. \\ Markus Knuf ${ }^{20,21} \cdot$ Klaus Marquard $^{22}$ - Thomas Mayer $^{23}$ - Sascha Meyer ${ }^{24} \cdot$ Hiltrud Muhle $^{25} \cdot$ Karen Müller-Schlüter $^{26}$. \\ Felix von Podewils ${ }^{27}$. Susanne Ruf ${ }^{28}$. Matthias Sauter ${ }^{29}$. Hannah Schäfer ${ }^{30,31}$. Jan-Ulrich Schlump ${ }^{32}$. \\ Steffen Syrbe ${ }^{33} \cdot$ Charlotte Thiels $^{34} \cdot$ Regina Trollmann $^{35} \cdot$ Adelheid Wiemer-Kruel $^{5} \cdot$ Bernd Wilken $^{36}$. \\ Bianca Zukunft ${ }^{37} \cdot$ Adam Strzelczyk $^{1,2,13}$ (])
}

Accepted: 21 June 2021 / Published online: 17 July 2021

(c) The Author(s) 2021

\begin{abstract}
Background The approval of everolimus (EVE) for the treatment of angiomyolipoma (2013), subependymal giant cell astrocytoma (2013) and drug-refractory epilepsy (2017) in patients with tuberous sclerosis complex (TSC) represents the first disease-modifying treatment option available for this rare and complex genetic disorder.

Objective The objective of this study was to analyse the use, efficacy, tolerability and treatment retention of EVE in patients with TSC in Germany from the patient's perspective.

Methods A structured cross-age survey was conducted at 26 specialised TSC centres in Germany and by the German TSC patient advocacy group between February and July 2019, enrolling children, adolescents and adult patients with TSC.

Results Of 365 participants, $36.7 \%$ ( $n=134)$ reported the current or past intake of EVE, including $31.5 \%(n=115)$ who were taking EVE at study entry. The mean EVE dosage was $6.1 \pm 2.9 \mathrm{mg} / \mathrm{m}^{2}$ (median: $5.6 \mathrm{mg} / \mathrm{m}^{2}, \mathrm{range} 2.0-15.1 \mathrm{mg} / \mathrm{m}^{2}$ ) in children and adolescents and $4 \pm 2.1 \mathrm{mg} / \mathrm{m}^{2}$ (median: $3.7 \mathrm{mg} / \mathrm{m}^{2}$, range $0.8-10.1 \mathrm{mg} / \mathrm{m}^{2}$ ) in adult patients. An early diagnosis of TSC, the presence of angiomyolipoma, drug-refractory epilepsy, neuropsychiatric manifestations, subependymal giant cell astrocytoma, cardiac rhabdomyoma and overall multi-organ involvement were associated with the use of EVE as a diseasemodifying treatment. The reported efficacy was $64.0 \%$ for angiomyolipoma ( $75 \%$ in adult patients), $66.2 \%$ for drug-refractory epilepsy, and $54.4 \%$ for subependymal giant cell astrocytoma. The overall retention rate for EVE was $85.8 \%$. The retention rates after 12 months of EVE therapy were higher among adults $(93.7 \%)$ than among children and adolescents $(88.7 \%$; $90.5 \%$ vs $77.4 \%$ after 24 months; $87.3 \%$ vs $77.4 \%$ after 36 months). Tolerability was acceptable, with $70.9 \%$ of patients overall reporting adverse events, including stomatitis $(47.0 \%)$, acne-like rash $(7.7 \%)$, increased susceptibility to common infections and lymphoedema (each $6.0 \%$ ), which were the most frequently reported symptoms. With a total score of 41.7 compared with 36.8 among patients not taking EVE, patients currently being treated with EVE showed an increased Liverpool Adverse Event Profile. Noticeable deviations in the sub-items 'tiredness', 'skin problems' and 'mouth/gum problems', which are likely related to EVE-typical adverse effects, were more frequently reported among patients taking EVE.

Conclusions From the patients' perspective, EVE is an effective and relatively well-tolerated disease-modifying treatment option for children, adolescents and adults with TSC, associated with a high long-term retention rate that can be individually considered for each patient. Everolimus therapy should ideally be supervised by a centre experienced in the use of mechanistic target of rapamycin inhibitors, and adverse effects should be monitored on a regular basis.
\end{abstract}

Clinical Trial Registration: This study was registered with the German Clinical Trials Register (DRKS00016045; Universal Trial Number: U1111-1229-4714).

Extended author information available on the last page of the article 


\section{Key Points}

Everolimus is a well-established disease-modifying therapy for tuberous sclerosis complex that is widely used in Germany for several disease manifestations

Everolimus appears to provide a good effect on drugrefractory epilepsies, subependymal giant cell astrocytoma, angiolipomas and cardiac rhabdomyoma

Over two-thirds of patients reported adverse events with everolimus, with stomatitis as the most frequent symptom $(47.0 \%)$, followed by immunosuppression and an acne-like rash

Adverse events frequently result in dose reductions, and cause approximately one-quarter of all patients $(22.4 \%)$ to temporarily discontinue therapy

Retention rates were high over the first 36 months in children, adolescents and adults

\section{Introduction}

Tuberous sclerosis complex (TSC) is a rare genetic disorder with a prevalence of up to 1 in 5000 individuals that is caused by genetic variations in either the TSC1 or TSC2 gene, which result in the loss of function [1-3]. Both genes encode components of the hamartin-tuberin complex and serve as tumour suppressor genes by downregulating cell proliferation and differentiation via mechanistic target of rapamycin (mTOR) [4, 5]. Tuberous sclerosis complex presents as distinct clinical manifestations in various organ systems, typically caused by the impairment of normal organ function by the development of benign rapidly growing tumours [6-8]. Children with TSC often develop severe drug-resistant epilepsy (DRE) shortly after birth or within their first year of life, which is characterised by infantile spasms, focal seizures and comorbid developmental delay, cognitive disabilities and neuropsychiatric symptoms [7-12]. Due to the often severe course of the disease, TSC represents an enormous burden for patients and their caregivers [13]. Moreover, high disease-related direct and indirect costs pose a strain on patients, their caregivers, and the public health systems [14, 15].

Following their discovery in 1975, mTOR inhibitors, such as sirolimus and everolimus (EVE), have increasingly been used to treat various tumour entities and following organ transplantation, supported by research examining the relationship between rapamycin and cell proliferation [16]. Everolimus was approved in 2013 by the European
Medicines Agency as a disease-modifying treatment (DMT) for patients with TSC who present with subependymal giant cell astrocytoma (SEGA), which is a low-grade astrocytic brain tumour (astrocytoma) that develops within the ventricle system. The approval of EVE use was extended by the European Medicines Agency to the treatment of renal angiomyolipoma in 2013 and focal seizures associated with DRE in 2017, allowing for the broad use of EVE to treat these three TSC manifestations [17-20]. Outside of these approved indications, EVE is also used off-label to treat other TSC-associated manifestations in severely affected patients, such as severe neuropsychiatric symptoms and cardiac rhabdomyoma (CRM) [21]. In general, the use of EVE in TSC has been shown to be feasible; however, data regarding the efficacy, retention, safety and tolerability of EVE from the patient's perspective are missing, and EVE has been associated with drug-related adverse events (AEs), including severe infections and isolated cases of reported deaths [22]. The aim of the present study was to analyse the use, efficacy, retention and tolerability of EVE among patients with TSC in Germany from the patient's point of view.

\section{Methods}

\subsection{Study Design}

This survey enrolled children, adolescents and adults with TSC through the German TSC patient advocacy group (Tuberöse Sklerose Deutschland e.V., Wiesbaden, Germany) and at 26 specialised TSC centres throughout Germany (Berlin, Bochum, Erlangen, Frankfurt, Freiburg, Giessen, Greifswald, Hannover, Herdecke, Heidelberg, Hirschaid, Homburg, Kassel, Kempten, Kiel, Kork, Leipzig, Lingen, Marburg, München, Münster, Neuruppin, Oberhausen, Radeberg [near Dresden], Rostock, Stuttgart, Tübingen, Vogtareuth and Wiesbaden). Written informed consent, obtained either from the patients themselves or from their legal guardians, was mandatory to participate in this study. The diagnosis of TSC was based on the recommendations of the 2012 International TSC Consensus Conference [23]. All patients who did not meet these criteria or for whom relevant data were missing ( $n=11)$ were excluded from the study. This study received approval from the Institutional Review Board of Goethe-University and was registered with the German Clinical Trials Register (DRKS00016045; Universal Trial Number: U1111-1229-4714). During conception, conduction and analysis of the present study, the STROBE guidelines (Strengthening The Reporting of Observational Studies in Epidemiology) were closely followed [24] to increase the reliability and accuracy of the data analysis. 


\subsection{Data Acquisition and Metrics}

Questionnaires were provided to adult patients with TSC or their primary caregivers, for example, in the case of a cognitive disability/incapacity, as well as to caregivers of children and adolescents with TSC between February and July 2019. All adult participants and the legal guardians of minor patients with TSC $(<18$ years of age) were asked to complete a retrospective paper-based questionnaire referencing the use of EVE and the associated efficacy and tolerability. The questionnaire used in this study was adapted for use in patients with TSC based on established questionnaires that have previously been validated in outcome research among populations of other chronically ill patients [25-28]. To increase the yield of the survey, both multiple-choice and free-text options were allowed to collect any relevant answers. The following options were available for the indication of efficacy for angiomyolipoma, SEGA or others: no effect, size increase, constant size and size decrease. The efficacy for DRE treatment was graded using the following items: no effect and seizure reduction by $25 \%, 50 \%$, $75 \%$ or $100 \%$ (complete cessation of seizures). To assess the tolerability of EVE, questions were systematically asked regarding adverse effects. In addition to the options of no AEs, stomatitis and increased susceptibility to common infections (e.g. frequent mild colds, pharyngitis and bronchitis), respondents were provided with the option of indicating and describing other adverse effects. In addition, each participant was asked whether EVE has been reduced or temporarily discontinued because of AEs. For further analysis, participants were divided into different subgroups according to their ages ( $<18$ years or $\geq 18$ years), general exposure to EVE (no exposure or one or more doses of EVE throughout their lifetime, 'lifetime prevalence') and whether they are currently receiving EVE therapy, using the study entry date as the reporting date. All information used in the study was based on the written statements provided by the patients themselves or their caregivers. Drug-related AEs were assessed using a free specification option and by employing the Liverpool Adverse Event Profile (LAEP). The LAEP is a well-established, 19-item self-report questionnaire that was initially developed to monitor the frequency and severity of common adverse effects associated with anti-seizure drugs (ASDs) and can also be used in other disorders associated with epilepsy [29, 30]. To allow for the basal distinction between $\mathrm{AE}$ categories associated with EVE and not caused by the concomitant intake of ASDs, the LAEP and its significant sub-items were also calculated separately for a subgroup of patients who were not taking ASDs. Health-related quality of life (HRQOL) was accessed using the well-established, age-specific by-proxy KINDL questionnaire for children and adolescents in the age group of $\geq 4-17$ years and the visual analogue scale of EQ-5L-5D
(EuroQOL Group) for adult patients ( $\geq 18$ years of age). In both questionnaires, HRQOL values can range between 0 (very poor) and 100 (very good) [31-33]. Treatment retention at study entry was calculated as the ratio of the number of patients reporting ongoing EVE therapy at the time of study enrolment to the number of patients who reported any lifetime prevalence of EVE.

As no reliable data were available for possible interactions between EVE and other drugs, this relationship or the attribution of fatigue in this regard could not be investigated within the scope of the study. This study assessed TSC relevant laboratory parameters, for example, cholesterol, however, these were very sparsely reported by patients or their caregivers precluding a statistical analysis.

\subsection{Data Entry and Statistical Analysis}

Statistical analysis was performed in SPSS Statistics 27 (IBM Corp., Armonk, NY, USA) using the non-parametric Kruskal-Wallis rank test to determine significant differences between ordinary items. For the comparison of processed data, an unpaired T-test was performed using the mean, standard deviation and number $(n)$. After post hoc corrections for multiple testing using the Benjamini-Hochberg method [34, 35], $p$ values $<0.05$ were regarded as significant. As the study design does not allow for a comparison of factors before and after/on EVE therapy, a multivariate analysis stepwise backwards regression based on all sociodemographic and disease-specific aspects as well as ASD number and AEs under EVE was used to identify factors that influence LAEP and HRQOL at the best possible rate [36]. Graphs were created using GraphPad Prism 7 (GraphPad Software, San Diego, CA, USA) and arranged using PixelmatorPro (Pixelmator Team, Vilnius, Lithuania).

\section{Results}

\subsection{Sociodemographic Data and Disease-Specific Aspects}

Overall, 365 participants were enrolled in this analysis. The mean age of the total study population was $22.1 \pm 15.4$ years (median: 19.0 years, range: $0.7-78.0$ years), with an equal sex distribution ( $49.3 \%$ female, $50.7 \%$ male). The mean age at the time of TSC diagnosis was $6.2 \pm 12.0$ years (median: 1.0 years), from a prenatal diagnosis at -0.33 years to 66 years. The mean age at the time of initial TSC manifestation was $3.3 \pm 9.0$ years (median: 1 year), from a prenatal manifestation at -0.25 years to 66 years. Most patients (38.4\%, $n=140$ ) reported a genetic variation in TSC2, including eight patients (2.2\%) reporting the TSC2/PKDI contiguous gene $(P K D T S)$, whereas $15.1 \%(n=55)$ reported a genetic 
variation in TSCl. The subgroup of children and adolescents with TSC comprised 166 patients $(45.5 \%)$, with a mean age of $9.3 \pm 5.0$ years (median: 9.6 years, range $0.7-17.9$ years), $47.0 \%$ of whom were female $(n=78)$. The subgroup of adults with TSC contained 199 patients (54.5\%), with a mean age of $32.8 \pm 12.7$ years (median: 30 years, range $18-78$ years).

\subsection{Use of mTOR Inhibitors}

Overall, 134 patients (36.7\%) reported the intake of at least one dose of EVE during their lifetimes (lifetime prevalence), and $115(31.5 \%)$ patients reported using EVE at the time of study entry. The mean current dose of EVE was $6.1 \pm$ $3.4 \mathrm{mg}$ per day (median: $5.0 \mathrm{mg}$ per day, range $0.5-15 \mathrm{mg}$ per day), with a mean dose in the subgroup of children and adolescents of $5.1 \pm 2.9 \mathrm{mg}$ per day (median: $5 \mathrm{mg}$ per day, range $0.5-12.5 \mathrm{mg}$ per day) and a mean dose in the adult subgroup of $6.8 \pm 3.5 \mathrm{mg}$ per day (median: $5 \mathrm{mg}$ per day, range; $1.5-15.0 \mathrm{mg}$ per day). These values corresponded with a mean dosage of $4.9 \pm 2.5 \mathrm{mg} / \mathrm{m}^{2}$ (median: $4.2 \mathrm{mg}$ / $\mathrm{m}^{2}$, range $0.8-15.1 \mathrm{mg} / \mathrm{m}^{2}$ ) for all patients, a mean of 6.1 $\pm 2.9 \mathrm{mg} / \mathrm{m}^{2}$ (median: $5.6 \mathrm{mg} / \mathrm{m}^{2}$, range $2.0-15.1 \mathrm{mg} / \mathrm{m}^{2}$ ) among children and adolescents, and a mean of $4 \pm 2.1 \mathrm{mg} /$ $\mathrm{m}^{2}$ (median: $3.7 \mathrm{mg} / \mathrm{m}^{2}$, range $0.8-10.1 \mathrm{mg} / \mathrm{m}^{2}$ ) among adult patients. Detailed sociodemographic and disease-specific characteristics of all cohorts are provided in Table 1.

Of note, systemic sirolimus was reported to be used in five female patients (1.4\%, mean age of $22.0 \pm 16.3$ years), none of whom was treated with EVE. Sirolimus in these patients was most often associated with the presence of lymphangioleiomyomatosis, consistent with reported benefits of sirolimus in case reports and a randomised controlled trial [37-39].

\subsection{Univariate Analysis of Sociodemographic and TSC-Specific Characteristics Associated with EVE Therapy}

Univariate analysis revealed that EVE was frequently used in patients with a disease manifestation within the first year of life ( $p=0.028)$, in patients diagnosed with angiomyolipoma $(p=0.006)$, DRE $(p=0.006)$, SEGA $(p=0.006), \operatorname{CRM}(p$ $=0.012)$ or neuropsychiatric symptoms $(p=0.012)$, and in patients with four or more affected organ systems $(p=$ 0.006 ). Everolimus therapy was also significantly frequently reported in patients using anticonvulsive polytherapy. Lymphangioleiomyomatosis was reported by 22 female patients, but its prevalence was not significantly associated with EVE therapy $(p=0.699)$. No other tested parameters were significantly associated with EVE use (Table 1). Healthrelated quality of life was lower in adult patients with an
EVE lifetime prevalence, with a mean value of $58.9 \pm 21.0$ (median: 60.0) compared with patients not exposed to EVE (mean $68.3 \pm 19.5$, median: $70.0, p=0.010$ ). The best fit $(\mathrm{F}=6.112, p=0.004)$ of multivariate stepwise regression analysis resulted in a model with two remaining factors, i.e. presence of EVE-associated AEs ( $p=0.089$, odds ratio [OR] 1.728) and active EVE treatment on study enrolment $(p=0.002$, OR 3.227). Health-related quality of life among children and adolescents did not differ between patients with and without EVE exposure $(p=0.460)$ and the multivariate analysis did not identify a model reaching a level of statistical significance. The best fit $(\mathrm{F}=2.516, p=0.082)$ was achieved in a model with AEs under EVE therapy as most relevant, but also a not-significantly contributing factor ( $p$ $=0.057$, OR 1.996). No overall differences in the numbers of ambulatory visits or blood draws were identified between patients with and without EVE exposure ( $p=0.862$ and $p=$ 0.061, respectively).

\subsection{Indications for EVE Therapy}

The majority of patients reported the intake of EVE because of multiple TSC-related symptoms $(56 \%, n=75)$, whereas only $43.3 \%(n=58)$ reported a single indication for mTOR inhibitor therapy. According to patients or their caregivers, the most common indications for systemic EVE therapy were DRE $(53.0 \%, n=71)$, angiomyolipoma $(52.2 \%, n=$ 70) and SEGA $(38.8 \%, n=52)$, followed by CRM $(12.7 \%$, $n=17)$, dermal TSC manifestations $(9.0 \%, n=12)$ and cerebral tubers $(3.7 \%, n=5)$. Angiomyolipoma was significantly more frequently reported as an EVE indication among adults than among children and adolescents $(p=0.007)$, whereas no other indication showed an age group dependence. Lymphangioleiomyomatosis was not reported as an explicit treatment indication by any participants. A detailed overview of the reported indications for EVE therapy is provided in Table 2.

\subsection{Efficacy of EVE Therapy}

For the three most common indications, DRE, SEGA and angiomyolipoma, an effect attributed to EVE was reported by $66.2 \%, 54.4 \%$ and $64.0 \%$ of participants, respectively, including reductions in seizure frequency, reductions in growth sizes or the prevention of further growths. The reported efficacies of EVE for CRM (14.2\%) and angiofibroma $(5.1 \%)$ were lower. No significant difference was identified between the two age subgroups regarding EVE efficacy for frequent indications. A detailed overview of EVE efficacy is provided in Table 3. 
Table 1 Sociodemographic and TSC-specific aspects, according to treatment with everolimus

\begin{tabular}{|c|c|c|c|c|}
\hline & All patients $(n=365)$ & No $\operatorname{EVE}(n=231)$ & $\operatorname{EVE}(n=134)$ & $p$ value $^{\mathrm{a}}$ \\
\hline \multicolumn{5}{|c|}{ Sociodemographic aspects, \% (n) } \\
\hline \multicolumn{5}{|c|}{ Age category, years } \\
\hline$<18$ & $45.5(166)$ & $46.3(107)$ & $44.0(59)$ & \multirow[t]{2}{*}{0.699} \\
\hline$\geq 18$ & 54.5 (199) & $53.7(124)$ & $56.0(75)$ & \\
\hline \multicolumn{5}{|l|}{ Sex } \\
\hline Female & $49.3(180)$ & $50.6(117)$ & $47.0(63)$ & \multirow[t]{2}{*}{0.649} \\
\hline Male & $50.7(185)$ & $49.4(114)$ & $53.0(71)$ & \\
\hline \multicolumn{5}{|c|}{ Disease manifestation, years } \\
\hline$<1$ & $43.6(159)$ & $38.1(88)$ & $53.0(71)$ & \multirow[t]{2}{*}{0.028} \\
\hline$\geq 1$ & $48.2(176)$ & $52.8(122)$ & $40.3(54)$ & \\
\hline \multicolumn{5}{|l|}{ Disease duration, years } \\
\hline$<15$ & $45.2(165)$ & $46.8(108)$ & $42.5(57)$ & \multirow[t]{2}{*}{0.530} \\
\hline$\geq 15$ & $46.6(170)$ & $44.2(102)$ & $50.7(68)$ & \\
\hline \multicolumn{5}{|c|}{ Disease-specific aspects, \% (n) } \\
\hline \multicolumn{5}{|l|}{ TSC mutation } \\
\hline$T S C 1^{\mathrm{b}}$ & $15.1(55)$ & $14.7(34)$ & $15.7(21)$ & \multirow[t]{3}{*}{0.699} \\
\hline$T S C 2^{\mathrm{b}}$ & $38.4(140)$ & $37.7(87)$ & $39.6(53)$ & \\
\hline n.a. & $46.6(170)$ & $47.6(110)$ & $44.8(60)$ & \\
\hline \multicolumn{5}{|l|}{ Organ manifestation } \\
\hline Kidney & $63.8(233)$ & $59.3(137)$ & $71.6(96)$ & 0.056 \\
\hline Angiomyolipoma & $52.3(191)$ & $45.5(105)$ & $64.2(86)$ & 0.006 \\
\hline $\mathrm{CRF}$ & $7.1(26)$ & $8.2(19)$ & $5.2(7)$ & 0.528 \\
\hline Renal cysts & 36.7 (134) & $35.1(81)$ & $39.6(53)$ & 0.599 \\
\hline Haematuria & $3.0(11)$ & $3.5(8)$ & $2.2(3)$ & 0.649 \\
\hline Anaemia & $3.8(14)$ & $3.5(8)$ & $4.5(6)$ & 0.699 \\
\hline Epilepsy & $82.2(300)$ & $81.0(187)$ & 84.3 (113) & 0.599 \\
\hline Refractory & $43.6(159)$ & $35.5(82)$ & $57.5(77)$ & 0.006 \\
\hline Psychiatric & $50.4(184)$ & $44.2(102)$ & $61.2(82)$ & 0.012 \\
\hline Structural brain & $74.8(273)$ & $71.0(164)$ & 81.3 (109) & 0.063 \\
\hline SEGA & $37.0(135)$ & $29.0(67)$ & $50.7(68)$ & 0.006 \\
\hline Tuber & 38.0 (139) & $38.5(89)$ & $37.3(50)$ & 0.818 \\
\hline Skin & $90.4(330)$ & $91.3(211)$ & 88.8 (119) & 0.599 \\
\hline Heart & $58.4(213)$ & $50.6(117)$ & $71.6(96)$ & 0.006 \\
\hline CRM & $42.2(154)$ & $36.4(84)$ & $52.2(70)$ & 0.012 \\
\hline Cardiac arrhythmia & $7.9(29)$ & $8.2(19)$ & $7.5(10)$ & 0.232 \\
\hline Hypertension & $16.7(61)$ & $13.4(31)$ & $22.4(30)$ & 0.065 \\
\hline Lung & $6.0(22)$ & $5.6(13)$ & $6.7(9)$ & 0.699 \\
\hline LAM & $6.0(22)$ & $5.6(13)$ & $6.7(9)$ & 0.699 \\
\hline Others & $34.5(126)$ & $30.3(70)$ & $41.7(56)$ & 0.065 \\
\hline Eye disease & $27.9(102)$ & $25.1(58)$ & $32.8(44)$ & 0.175 \\
\hline Obesity & $19.2(70)$ & $20.3(47)$ & $17.2(23)$ & 0.599 \\
\hline \multicolumn{5}{|c|}{ Number of affected organ systems } \\
\hline $1-3$ & $24.7(90)$ & $32.0(74)$ & $11.9(16)$ & \multirow[t]{2}{*}{0.006} \\
\hline$\geq 4$ & $75.3(275)$ & $68.0(157)$ & $88.1(118)$ & \\
\hline
\end{tabular}

$C R F$ chronic renal failure, $C R M$ cardiac rhabdomyoma, $E V E$ everolimus, $L A M$ lymphangioleiomyomatosis, n.a. not available, SEGA subependymal giant cell astrocytoma, TSC tuberous sclerosis complex

${ }^{a}$ Calculated between EVE and non-EVE subgroups using the Kruskal-Wallis test with post hoc correction for multiple testing using the Benjamini-Hochberg method

${ }^{\mathrm{b}}$ Calculated between TSC1 and TSC2 


\subsection{Safety and Tolerability of EVE Therapy}

Overall, 70.9\% $(n=95)$ of all patients reported AEs during EVE therapy, which led to a dose reduction or temporary discontinuation in $22.4 \%(n=30)$. Adverse events were significantly more frequently reported among adult patients than among children and adolescents $(p=0.036)$. The most frequently reported AEs were stomatitis (47.0\%, $n=63)$, acne-like rash $(7.7 \%, n=10)$, general symptoms of immunosuppression $(6.0 \%, n=8)$, lymphoedema $(6.0 \%$, $n=8)$ and the deterioration of a patient's general condition $(5.2 \%, n=7)$. Wound-healing difficulties were reported by three patients (2.2\%). The relative frequencies of each $\mathrm{AE}$ did not differ significantly between the minor patients and adult patients with TSC in our cohort. Detailed information regarding AE frequency as well as general safety and tolerability of EVE therapy is provided in Tables 4 and 5 .

The mean number of ASDs being used was $1.8 \pm 0.78$ among the total population, including $1.7 \pm 0.8$ among patients not currently taking EVE and $2.0 \pm 0.74$ among patients currently taking $\operatorname{EVE}(p=0.043)$. In the subgroup of patients currently taking EVE, $24.3 \%$ reported no concomitant ASD intake, whereas 18.2\% stated the use of one ASD, and $57.4 \%$ reported the use of two or more ASDs. Among patients not currently being treated with EVE, $27.6 \%, 33.2 \%$ and $39.2 \%$, respectively reported the use of zero, one or multiple ASDs. Further information regarding the ASD regimes and the corresponding LAEP scores is provided in Table 5.

The mean LAEP score was $38.2 \pm 10.9$ (median: 37.0 ) for all enrolled patients. The mean LAEP score was significantly higher among patients currently being treated with
EVE (mean: $41.7 \pm 11.9)$ compared with patients not receiving EVE treatment (mean; $36.8 \pm 10.2, p=0.011$ ). Significant differences in the LAEP score were observed between patients without concomitant ASD therapy being currently treated or not treated with EVE (EVE 41.4 vs no EVE 34.2, $n=97 ; p=0.003$ ). Comparing patients taking an ASD monotherapy, the LAEP score was significantly higher in those taking $\mathrm{EVE}(\mathrm{EVE}=40.7$ vs no $\mathrm{EVE}=37.0, n=104$, $p=0.003$ ). The LAEP score was also significantly higher in patients taking EVE and an ASD polytherapy $(\mathrm{EVE}=42.3$ vs no $\mathrm{EVE}=38.5, n=164, p=0.003)$. When examining individual LAEP items, the EVE population revealed significantly higher scores for 'tiredness' $(p=0.006)$, 'problems with the skin' ( $p=0.019)$, 'trouble with mouth/gums' ( $p=$ $0.006)$ and 'sleepiness' $(p=0.006)$ compared with patients not using EVE. In patients without concomitant ASD therapy, only 'tiredness' $(p=0.010)$, 'problems with the skin' $(p=0.024)$ and 'trouble with mouth/gums' $(p=0.005)$ remained significant. Detailed information describing the LAEP results, and associated items are provided in Table 5 and displayed in Fig. 2. The best fit $(\mathrm{F}=11.431, p<0.001)$ of multivariate regression analysis resulted in a model with three remaining factors, i.e. number of concomitant ASDs ( $p=0.062$, OR 1.931), presence of AEs ( $p=0.005$, OR $2.987)$ and presence of psychiatric comorbidities $(p=0.001$, OR 3.819).

\subsection{Duration and Retention of EVE Therapy}

Therapeutic retention at study entry was $85.8 \%$, as 115 were still using EVE therapy of 134 patients with a lifetime prevalence of EVE. Among all patients with a known

Table 2 Frequent indications for everolimus therapy in all patients exposed to everolimus

\begin{tabular}{llll}
\hline & Total $(n=134)$ & Children $(n=59)$ & Adults $(n=75)$ \\
\hline Number of indications, \% $(n)^{\mathrm{a}, \mathrm{c}}$ & & & $45.3(34)$ \\
1 & $43.3(58)$ & $40.7(24)$ & $26.7(20)$ \\
2 & $30.6(41)$ & $35.6(21)$ & $28.0(21)$ \\
$\geq 3$ & $25.4(34)$ & $22.0(13)$ & \\
Indication, $\%(n)^{\mathrm{a}}$ & & & $42.7(32)$ \\
DRE & $53.0(71)$ & $66.1(39)$ & $76.0(57)$ \\
Angiomyolipoma & $52.2(70)$ & $22.0(13)$ & $34.7(26)$ \\
SEGA & $38.8(52)$ & $44.1(26)$ & $14.7(11)$ \\
CRM & $12.7(17)$ & $10.2(6)$ & $4.0(3)$ \\
Dermal manifestation & $9.0(12)$ & $15.3(9)$ & $5.3(4)$ \\
Cerebral tuber & $3.7(5)$ & $1.7(1)$ & 0.263 \\
\hline
\end{tabular}

$C R M$ cardiac rhabdomyoma, DRE drug-refractory epilepsy, EVE everolimus, SEGA subependymal giant cell astrocytoma

${ }^{\mathrm{a}}$ Calculated for patients who reported one or more indication for EVE therapy $(n=60)$

${ }^{\mathrm{b}}$ Calculated between EVE and non-EVE subgroups using the Kruskal-Wallis test with post hoc correction for multiple testing using the Benjamini-Hochberg method

${ }^{\mathrm{c}}$ Calculated over all given sub-items 
Table 3 Reported efficacy of everolimus therapy on different organ manifestations in all patients exposed to everolimus

\begin{tabular}{|c|c|c|c|c|}
\hline & Total $(n=134)$ & Children $(n=59)$ & Adults $(n=75)$ & $p$ value $^{\mathrm{b}}$ \\
\hline Drug-refractory epilepsy, $\%(n)^{\mathrm{a}}$ & $(n=77)$ & $(n=38)$ & $(n=39)$ & \\
\hline Attributable effect on seizure reduction & $66.2(51)$ & $71.1(27)$ & $61.5(24)$ & 0.289 \\
\hline Seizure reduction $<50 \%$ & $22.0(17)$ & $18.4(7)$ & $25.6(10)$ & \\
\hline Seizure reduction $\geq 50 \%$ & $33.8(26)$ & $39.5(15)$ & $28.2(11)$ & \\
\hline Seizure free & $10.4(8)$ & $13.2(5)$ & $7.7(3)$ & \\
\hline Subependymal giant cell astrocytoma, $\%(n)^{\mathrm{a}}$ & $(n=68)$ & $(n=30)$ & $(n=38)$ & \\
\hline Attributable effect & $54.4(37)$ & $73.3(22)$ & $39.5(15)$ & 0.989 \\
\hline Size reduction & $29.4(20)$ & $40.0(12)$ & $21.1(8)$ & \\
\hline Constant size & $25.0(17)$ & $33.3(10)$ & $18.4(7)$ & \\
\hline Angiomyolipoma, $\%(n)^{\mathrm{a}}$ & $(n=86)$ & $(n=26)$ & $(n=60)$ & \\
\hline Attributable effect & $64.0(55)$ & $38.5(10)$ & $75.0(45)$ & 0.070 \\
\hline Size reduction & $29.1(25)$ & $3.8(1)$ & $40.0(24)$ & \\
\hline Constant size & $34.9(30)$ & $34.6(9)$ & $35.0(21)$ & \\
\hline Cardiac rhabdomyoma, $\%(n)^{\mathrm{a}}$ & $(n=70)$ & $(n=43)$ & $(n=27)$ & \\
\hline Attributable effect & $14.2(10)$ & $14.0(6)$ & $14.8(4)$ & 0.987 \\
\hline Size reduction & $12.8(9)$ & $11.6(5)$ & $14.8(4)$ & \\
\hline Termination of cardiac arrhythmia & $1.4(1)$ & $2.3(1)$ & $0.0(0)$ & \\
\hline Angiofibroma, $\%(n)^{\mathrm{a}}$ & $(n=99)$ & $(n=30)$ & $(n=69)$ & \\
\hline Size reduction & $5.1(5)$ & $0.0(0)$ & $7.2(5)$ & \\
\hline
\end{tabular}

${ }^{a}$ Calculated based on the number of patients reporting the individual tuberous sclerosis complex manifestation and the intake of everolimus ${ }^{\mathrm{b}}$ Calculated using the Kruskal-Wallis test with post hoc correction for multiple testing using the Benjamini-Hochberg method for the overall attributable effect

Table 4 Safety and tolerability of everolimus treatment in all patients exposed to everolimus

\begin{tabular}{|c|c|c|c|c|}
\hline & Total $(n=134)$ & Children $(n=59)$ & Adults $(n=75)$ & $p$ value \\
\hline \multicolumn{5}{|l|}{ Severity of AEs, $\%(n)^{\mathrm{a}}$} \\
\hline Patients with AEs & $70.9(95)$ & $59.3(35)$ & $80.0(60)$ & 0.036 \\
\hline AEs leading to EVE reduction & $22.4(30)$ & $20.3(12)$ & $24.0(18)$ & 0.368 \\
\hline $\begin{array}{l}\text { AEs leading to temporally EVE discontinu- } \\
\text { ation }\end{array}$ & $22.4(30)$ & $27.1(16)$ & $18.7(14)$ & 0.960 \\
\hline \multicolumn{5}{|l|}{ Frequent AEs, $\%(n)^{\mathrm{a}}$} \\
\hline Stomatitis & $47.0(63)$ & $40.7(24)$ & $52.0(39)$ & 0.448 \\
\hline Acne-like rash & $7.7(10)$ & $1.7(1)$ & $12.0(9)$ & 0.090 \\
\hline Symptoms of immunosuppression & $6.0(8)$ & $13.6(8)$ & $9.3(7)$ & 0.561 \\
\hline Lymphoedema & $6.0(8)$ & $3.4(2)$ & $8.0(6)$ & 0.449 \\
\hline Deterioration of general condition & $5.2(7)$ & $1.7(1)$ & $8.0(6)$ & 0.368 \\
\hline Diarrhoea & $4.5(6)$ & $3.4(2)$ & $5.3(4)$ & 0.757 \\
\hline Fever & $3.7(5)$ & $6.8(4)$ & $1.3(1)$ & 0.368 \\
\hline Oral aphthae & $3.7(5)$ & $1.7(1)$ & $5.3(4)$ & 0.448 \\
\hline Pneumonia & $3.0(4)$ & $1.7(1)$ & $4.0(3)$ & 0.602 \\
\hline Wound-healing difficulties & $2.2(3)$ & $1.7(1)$ & $2.7(2)$ & 0.809 \\
\hline Extensive coughing & $1.5(2)$ & $3.4(2)$ & $0.0(0)$ & 0.372 \\
\hline Hair loss & $1.5(2)$ & $1.7(1)$ & $1.3(1)$ & 0.896 \\
\hline Inflammation in the genital area & $0.7(1)$ & $1.7(1)$ & $0.0(0)$ & 0.448 \\
\hline Molluscum contagiosum & $0.7(1)$ & $1.7(1)$ & $0.0(0)$ & 0.448 \\
\hline
\end{tabular}

AEs adverse events, $E V E$ everolimus

${ }^{\text {a }}$ Calculated per 134 patients that have reported the intake of at least 1 dose of EVE

${ }^{\mathrm{b}}$ Calculated using the Kruskal-Wallis test with post hoc correction for multiple testing using the Benjamini-Hochberg method 
EVE start date and either currently using EVE therapy or with a reported date of withdrawal, the retention rates were 91.4\% $(n=106 / 116)$ after 12 months, 84.5\% $(n=98 / 116)$ after 24 months and 82.8\% ( $n=96 / 116)$ after 36 months, with a reported mean EVE therapy duration of $1210 \pm 991$ days (median: 821 days, range 1-3883 days). Everolimus therapy retention was significantly higher for adult patients $(p=0.049)$ compared with children and adolescents. More information regarding EVE therapy duration and retention is provided in Table 6. A Kaplan-Meier diagram illustrating EVE therapy retention for the total study population and for both age-related subgroups is displayed in Fig. 1.

Table 5 Univariate analysis of a relationship between the LAEP score and the current intake of everolimus in patients with and without concomitant use of anti-seizure drugs

\begin{tabular}{|c|c|c|c|c|c|c|c|}
\hline & \multicolumn{2}{|c|}{ All patients $(n=365)$} & \multicolumn{2}{|c|}{ No EVE $(n=250)$} & \multicolumn{2}{|c|}{$\operatorname{EVE}(n=115)$} & \multirow[t]{2}{*}{$p$ value $^{\mathrm{a}}$} \\
\hline & Mean & $\pm \mathrm{SD}$ & Mean & $\pm \mathrm{SD}$ & Mean & $\pm \mathrm{SD}$ & \\
\hline \multicolumn{8}{|l|}{ LAEP items } \\
\hline Total score & 38.2 & 10.9 & 36.8 & 10.2 & 41.7 & 11.9 & 0.009 \\
\hline Total score ${ }^{\mathrm{b}}$ & 36.6 & 11.6 & 34.2 & 11.1 & 41.4 & 11.2 & 0.013 \\
\hline Unsteadiness & 1.9 & 1.0 & 1.8 & 1.0 & 2.0 & 1.1 & 0.058 \\
\hline Tiredness & 2.6 & 1.9 & 2.4 & 1.0 & 2.9 & 1.0 & 0.006 \\
\hline Tiredness $^{\mathrm{b}}$ & 2.6 & 1.0 & 2.3 & 1.0 & 3.0 & 1.0 & 0.010 \\
\hline Restlessness & 2.4 & 1.1 & 2.3 & 1.1 & 2.6 & 1.1 & 0.064 \\
\hline Feelings of aggression & 2.3 & 1.0 & 2.2 & 1.0 & 2.5 & 1.1 & 0.067 \\
\hline Nervousness & 2.4 & 1.0 & 2.3 & 1.0 & 2.5 & 1.0 & 0.096 \\
\hline Headache & 1.9 & 0.9 & 1.9 & 0.9 & 2.0 & 0.9 & 0.575 \\
\hline Hair loss & 1.3 & 0.8 & 1.3 & 0.7 & 1.4 & 0.9 & 0.264 \\
\hline Problems with the skin & 2.3 & 1.1 & 2.2 & 1.1 & 2.5 & 1.0 & 0.019 \\
\hline Problems with the skin ${ }^{\mathrm{b}}$ & 2.2 & 1.2 & 2.0 & 1.2 & 2.7 & 1.2 & 0.024 \\
\hline Double/blurred vision & 1.5 & 0.8 & 1.4 & 0.7 & 1.7 & 1.0 & 0.064 \\
\hline Upset stomach & 1.8 & 0.9 & 1.7 & 0.9 & 1.9 & 1.0 & 0.239 \\
\hline Trouble with mouth/gums & 2.1 & 1.1 & 1.9 & 1.0 & 2.5 & 1.1 & 0.006 \\
\hline Trouble with mouth/gums ${ }^{\text {b }}$ & 1.9 & 1.0 & 1.7 & 0.9 & 2.5 & 1.0 & 0.005 \\
\hline Difficulty concentrating & 2.8 & 1.1 & 2.7 & 1.1 & 2.9 & 1.0 & 0.327 \\
\hline Tremor, shaky hands & 1.7 & 1.0 & 1.6 & 0.9 & 1.8 & 1.1 & 0.253 \\
\hline Weight gain & 1.8 & 1.1 & 1.8 & 1.1 & 1.9 & 1.1 & 0.242 \\
\hline Dizziness & 1.6 & 0.8 & 1.5 & 0.8 & 1.7 & 0.9 & 0.253 \\
\hline Sleepiness & 2.0 & 1.0 & 1.8 & 1.0 & 2.3 & 1.1 & 0.006 \\
\hline Sleepiness $^{\mathrm{b}}$ & 1.9 & 1.0 & 1.8 & 1.0 & 2.2 & 1.0 & 0.062 \\
\hline Symptoms of depression & 1.6 & 0.9 & 1.5 & 0.9 & 1.7 & 1.0 & 0.117 \\
\hline Memory problems & 2.2 & 1.1 & 2.1 & 1.1 & 2.3 & 1.1 & 0.288 \\
\hline Disturbed sleep & 2.3 & 1.1 & 2.2 & 1.1 & 2.4 & 1.1 & 0.120 \\
\hline Oedema, other & 1.2 & 1.2 & 1.1 & 1.1 & 1.4 & 1.4 & 0.120 \\
\hline \multicolumn{8}{|l|}{ Use of ASDs } \\
\hline \multicolumn{8}{|l|}{ Number of ASD \% $(n)$} \\
\hline 0 (no intake) & \multicolumn{2}{|c|}{$26.6(97)$} & \multicolumn{2}{|l|}{$27.6(69)$} & \multicolumn{2}{|l|}{$24.3(28)$} & 0.006 \\
\hline 1 (ASD monotherapy) & \multicolumn{2}{|c|}{$28.5(104)$} & \multicolumn{2}{|l|}{$33.2(83)$} & \multicolumn{2}{|l|}{$18.2(21)$} & \\
\hline$\geq 2$ (ASD polytherapy) & \multicolumn{2}{|c|}{$44.9(164)$} & \multicolumn{2}{|l|}{$39.2(98)$} & \multicolumn{2}{|l|}{$57.4(66)$} & \\
\hline \multicolumn{8}{|l|}{ LAEP per ASD regime } \\
\hline 0 (no intake) & 36.6 & 11.6 & 34.2 & 11.1 & 41.4 & 11.2 & 0.003 \\
\hline 1 (ASD monotherapy) & 37.7 & 10.5 & 37.0 & 9.9 & 40.7 & 13.0 & 0.003 \\
\hline$\geq 2$ (ASD polytherapy) & 39.9 & 10.7 & 38.5 & 9.5 & 42.3 & 12.1 & 0.003 \\
\hline
\end{tabular}

$A S D$ anti-seizure drug, EVE everolimus, LAEP Liverpool Adverse Event Profile, SD standard deviation

${ }^{a}$ Calculated using the Kruskal-Wallis test with post hoc correction for multiple testing using the Benjamini-Hochberg method

${ }^{\mathrm{b}}$ Calculated for patients without the intake of concomitant ASDs (total all patients $n=97$; no EVE $n=69$; EVE $n=28$ ) 


\section{Discussion}

In line with the licensing guidelines established by the European Medicines Agency, EVE was predominantly used to treat DRE, SEGA and angiomyolipoma $[22,40]$. The agerelated increase in the use of EVE to treat angiomyolipoma is consistent with the increasing extent and severity of secondary chronic kidney disease during the course of TSC [ 41 , 42]. In addition, the occasional off-label use of EVE to treat other relevant TSC manifestations, such as CRM or severe neuropsychiatric symptoms, was also reported, which supports the use of EVE as a feasible, safe and well-tolerated therapeutic option after an individual benefit-risk assessment $[43,44]$. Therapy with EVE was typically associated with more than one disease manifestation in most patients and was associated with a lower HRQOL among adult patients, which is in line with previous studies and indicates that EVE is used more frequently among patients with a higher number of affected organs or more severe disease manifestations [45]. Because cutaneous TSC manifestations are predominantly treated topically with sirolimus, the low number of patients stating a dermal manifestation as an indication for EVE therapy in our study was reasonable [46]; however, beneficial effects of oral mTOR inhibitors against angiofibroma and shagreen patches have recently been demonstrated in patients with skin tumours as the primary disease manifestation and as a secondary effect in individuals being treated with EVE due to SEGA and angiomyolipoma [47, 48].

The efficacy of EVE for the treatment of various TSC symptoms has been extensively studied during the last years [49]. In the present study, efficacy was remarkably high for the treatment of DRE, SEGA and angiomyolipoma, with over $50 \%$ of patients being treated for each symptom reporting an effect that could be attributed to EVE therapy. Using the criteria of $a \geq 50 \%$ seizure reduction as an established measure for therapeutic efficacy in epilepsy, the $33.8 \%$ efficacy reported in this study is in line with previous studies showing seizure reductions $\geq 50 \%$ in between 30 and $50 \%$ of the study populations of most of the larger studies [50-58]. Although a lively debate is ongoing regarding how long EVE treatment should be continued before an effect on seizures can be expected, our data show that treatment success can be achieved within an interval of 1-3 years [59]. The responder rate is comparable to other modern ASDs, such as brivaracetam, perampanel, eslicarbazepine acetate or cenobamate, which highlights the potential of EVE treatment for TSC-related DRE [60-70]. In SEGA, size reductions under EVE therapy have frequently been used as therapeutic success markers. In the present cohort, a size reduction was reported for $29 \%$ of the participants, which is in line with previous publications reporting a treatment response for $32-42 \%$ of cases [71-73]. Size reductions or the prevention of further growth in TSC-related angiomyolipoma was reported by $64 \%$ of the current study

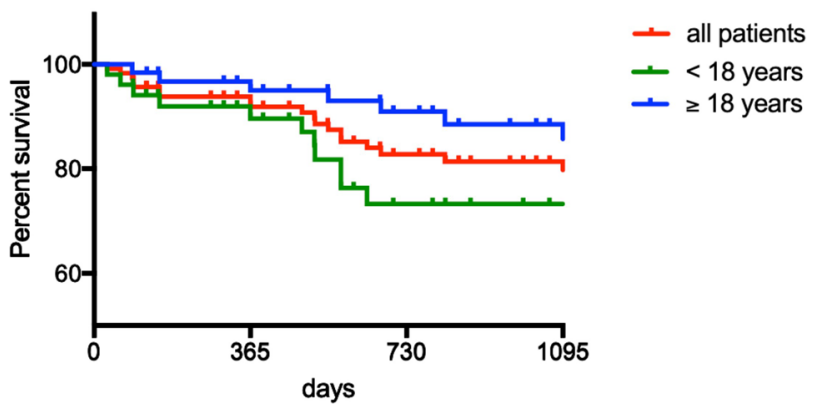

Fig. 1 Everolimus therapy retention displayed as a Kaplan-Meier survival diagram for minor patients $(n=53)$ and adult patients $(n$ $=63$ ) with tuberous sclerosis complex. Retention at study entry was $85.8 \%$, retention rates after 1,2 and 3 years of everolimus therapy were $91.4 \%, 84.5 \%$ and $82.8 \%$, respectively. Retention in adult patients was significantly better than retention in children and adolescents $(n=116, \log$-rank-test, $p=0.049)$

Table 6 Everolimus therapy adherence and retention

\begin{tabular}{llll}
\hline & All patients $(n=116)$ & Children $(n=53)$ & Adults $(n=63)$ \\
\hline $\begin{array}{l}\text { Intake duration, days }{ }^{\mathrm{a}} \\
\quad \text { Mean } \pm \text { SD }\end{array}$ & $1210 \pm 991$ & & $p$ value \\
Median & 821 & $949 \pm 874$ & $1424 \pm 1035$ \\
Range & $1-3883$ & $1-3103$ & 1111 \\
Retention rates, $\%(n)^{\mathrm{a}}$ & & & $89-3883$ \\
First year (at 365 days) & $91.4(106)$ & $88.7(47)$ & $93.7(59)$ \\
Second year (at 730 days) & $84.5(98)$ & $77.4(41)$ & $90.5(57)$ \\
Third year (at 1095 days) & $82.8(96)$ & $77.4(41)$ & $87.3(55)$ \\
\hline
\end{tabular}

EVE everolimus, $S D$ standard deviation

${ }^{a}$ Calculated based on all patients with a defined starting and endpoint for EVE therapy or ongoing therapy

${ }^{\mathrm{b}}$ Calculated using the log-rank test based on all patients with a defined starting and endpoint for EVE therapy or ongoing therapy 


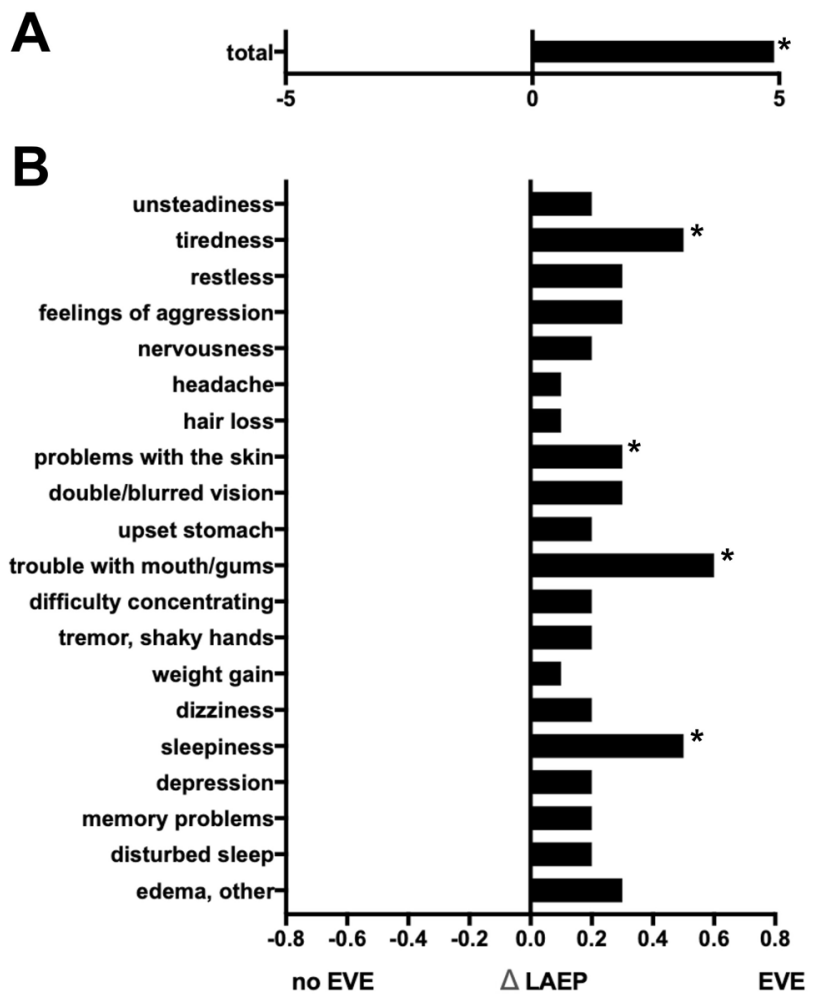

Fig. 2 Deviation of the mean Liverpool Adverse Event Profile (LAEP) total score (A) and sub-scores ( $\Delta$ LAEP, B) between patients with tuberous sclerosis complex currently treated with and without everolimus (EVE). A deviation of the bar to the right indicates a higher scale value in the EVE group, indicating a higher burden due to drug-related adverse events. All significant deviations are marked with an asterisk (*; $p<0.05)$. The analysis of only those patients without the concomitant intake of anti-seizure drugs revealed that the differences in the LAEP total score and those in the sub-scores of 'tiredness', 'problems with the skin' and 'trouble with mouth/gum' remained significant, indicating relevant EVE-related adverse-event burden for these subscales

participants, which is comparable to the published responder rates of 50-60\%. In angiomyolipoma, a possible benefit of low-dose EVE therapy $(5 \mathrm{mg})$ has recently been reported for adult patients, which resulted in a similar efficacy compared with high-dose therapy $(10 \mathrm{mg})$ and was associated with a more favourable AE profile [74]. A valid comparison of the efficacy of EVE treatment for rarer TSC-related indications, such as CRM, tubers and neuropsychiatric symptoms, cannot be adequately performed because of the low numbers reported in this study; however, for the treatment of CRM, case reports describing newborns and infants have shown an individual benefit of EVE treatment against CRM, with a frequently reported recurrence after EVE discontinuation $[75,76]$. Lymphangioleiomyomatosis was rarely reported in the present cohort and was never reported as an indication for EVE therapy; therefore, the effect of EVE for lymphangioleiomyomatosis treatment could not be assessed; however, several case reports and a randomised controlled trial have demonstrated the effects of mTOR inhibitor treatment on lymphangioleiomyomatosis in general [77].

Health-related quality of life was lower in adult patients with an EVE lifetime prevalence, compared with patients not exposed to EVE. A multivariate analysis revealed a current EVE treatment at study enrolment as an individual contributing factor for lower HRQOL. This effect could not be determined in children and adolescents with TSC, which may be owing to the general complexity of measuring HRQOL in children and adolescents [78]. To our knowledge, this is the first study highlighting this aspect, in contrast to other studies that have revealed no effect of EVE treatment on HRQOL in patients with neuroendocrine tumours [79].

Safety and tolerability are important issues for EVE therapy, as drug-related AEs have frequently been reported, although the frequency of AEs in controlled trials appears to be higher than those reported in post-marketing studies $[58,80]$. Comparable to previously reported retrospective studies, over $70 \%$ of patients in our study reported EVE-related AEs, which were more frequently reported (80\%) among the adult cohort than among children and adolescents $(59 \%)$ [18, 57, 81]. In addition to a potential increased willingness to report AEs among adult patients, the underestimation of AEs among children and adolescents due to by-proxy recording of AEs based on the responses of parents and guardians may be a factor in this difference, although this appears to be unlikely according to the literature $[82,83]$. In line with the most pivotal and post-marketing studies, frequently reported AEs included stomatitis, symptoms of immunosuppression, trivial infections and an acne-like rash $[17,18,51]$. In the present cohort, frequent dose reductions in response to AEs were reported, which is in line with current international recommendations for the management of relevant AEs during mTOR inhibitor therapy [80]. As another approach to assess tolerability, the individual LAEP was calculated to characterise the AE profiles of patients being treated with or naïve to EVE. Patients who reported EVE exposure showed a significantly higher LAEP total score, indicating a higher burden due to AEs (Table 5, Fig. 2A). Moreover, several LAEP sub-items (Table 5, Fig. 2B) were significantly increased in the EVE-exposed population. Because of the study design, no reliable causal relationships can be established between these individual LAEP items and the use of EVE; however, the increased sub-scores observed for 'skin problems' and 'problems of the mouth or gums' appear to match the characteristic AEs that have been reported for mTOR inhibitors [80]. Other nonspecific symptoms, such as 'dizziness', 'fatigue', 'drowsiness' and 'restlessness', might reflect a more severely affected patient collective or be associated with AEs caused by other medications [84]. To approach the problem of the 
lack of a causal relationship between LAEP and EVE exposure, a multivariate backward stepwise regression was performed highlighting the presence of EVE-associated AEs and of psychiatric comorbidities as relevant contributors. These results further support the impact of EVE therapy on LAEP in patients with TSC. The correlation of high LAEP scores and psychiatric diseases is a well-described aspect, that had already been shown in the validation studies and is therefore not surprising [85]. Interestingly, the numbers of outpatient follow-ups and blood draws did not significantly increase in the EVE population, which is likely owing to the generally frequent health encounters experienced by patients with TSC $[1,14,15]$.

The observed mean therapy duration of 1210 days (3.3 years) and the retention rates of $>90 \%$ for the first year and $>80 \%$ for the second and the third years indicated that therapy adherence to EVE was high in the current study, despite the frequently reported tolerability issues. In general, adherence to EVE therapy was higher among adult patients than among children and adolescents with TSC. These findings are in line with a previous retrospective study that reported a retention rate of $98 \%$ after 6 months of therapy [58]. As visualised in the Kaplan-Meier survival diagram (Fig. 1), EVE therapy appears most likely to be discontinued within the first months after therapy onset. This early peak of cessation is likely associated with intolerable AEs, similar to previous reports that mTOR therapy discontinuations due to AEs occur most frequently during the first 5 months of therapy [86]. Among children and adolescents with TSC, a notable number of EVE dropouts was reported during the second year of therapy, which can most likely be explained by a lack of effectiveness for the individual case. A lack of reliable evidence exists regarding the optimal length of preventative treatment using EVE or other DMTs in children and adolescents [59]. Moreover, the temporary discontinuation of EVE treatment for medical reasons, such as live vaccinations, must also be considered when evaluating treatments in infants and small children [80].

As with any questionnaire-based survey, this study may suffer from certain methodological limitations that could impact the evaluation and transferability of the results. The potential of selection bias owing to differences in the willingness to participate in studies across different population strata must be considered. Subjective perceptions, and recall bias, particularly regarding the severity of AEs and efficacy, may also influence the analyses in this study. Furthermore, the varying incidence of different TSC manifestations in children vs adult patients as well as a missing approval of EVE for several organ manifestations in early ages may have had an influence on the observed results. As no reliable data were available for possible interactions between EVE and other drugs, this relationship could not be investigated within the scope of the study. Unfortunately, the reporting of laboratory parameters was not sufficient for a statistical evaluation. Moreover, regional or national particularities may have influenced the results; however, the use of established questionnaires and compliance with the STROBE criteria [87] were applied to minimise these aspects to the extent that was reasonably possible.

\section{Conclusions}

In Germany, EVE is an established DMT for children, adolescents and adults with TSC. The use of EVE typically follows established marketing authorisation guidelines for DRE, SEGA and angiomyolipoma, but off-label use in patients with CRM and neuropsychiatric symptoms was also noted. The effects of EVE, especially for DRE, SEGA and angiomyolipoma, are considerable, and the tolerability appears to be acceptable. It is well known that the treatment of patients with TSC is highly complex and requires close interdisciplinary coordination. In particular, owing to frequent and sometimes severe AEs, which can require dose reductions or the temporary suspension of therapy, regular AE monitoring should be performed. Even if a better access to EVE would be desirable, treatment should be administered by or at least under the guidance of a centre that is experienced in the use and management of mTOR inhibitors in TSC.

\section{Declarations}

Funding Open Access funding enabled and organized by ProjektDEAL. This work was supported by the federal state Hessen with a LOEWE grant to the Center of Personal and Translational Epilepsy Research (CePTER)

Conflict of interest Laurent M. Willems has no conflicts of interest that are directly relevant to the content of this article. Felix Rosenow reports personal fees from Arvelle Therapeutics, Eisai GmbH, GW Pharmaceuticals, Novartis, Medtronic, and UCB and grants from the Detlev-Wrobel-Fonds for Epilepsy Research, the Deutsche Forschungsgemeinschaft, the LOEWE Programme of the State of Hesse and the European Union. Susanne Schubert-Bast reports personal fees from Eisai, Desitin Pharma, GW Pharmaceuticals companies, LivaNova, UCB and Zogenix. Gerhard Kurlemann reports personal fees from Desitin Arzneimittel, Eisai, GW Pharmaceuticals companies, UCB, Novartis, Takeda and Zogenix. Johann Philipp Zöllner reports speakers' honoraria and travel grants from Eisai and Desitin Arzneimittel. Thomas Bast reports personal fees from Eisai, Desitin Arzneimittel, GW Pharma, Novartis, Nutricia, Shire, Takeda, UCB Pharma and Zogenix. Astrid Bertsche reports personal fees from Desitin Arzneimittel $\mathrm{GmbH}$, Eisai GmbH, GW Pharma GmbH, Shire/Takeda GmbH, UCB Pharma GmbH and ViroPharma GmbH. Daniel Ebrahimi-Fakhari reports personal fees from GW Pharmaceuticals companies. Christoph Hertzberg reports personal fees from Desitin Arzneimittel, Eisai, GW Pharmaceuticals companies, Novartis, Shire and Zogenix. Ilka Immisch reports personal fees from UCB Pharma GmbH. Julia Jacobs reports personal fees from Eisai, GW Pharmaceuticals companies and Zogenix and has been supported by the German Research Foundation 
(DFG; JA 1725/4-1). Karl Martin Klein reports personal fees from UCB Pharma, Novartis Pharma AG, Eisai and GW Pharmaceuticals, grants from the federal state Hessen through the LOEWE program and grants from the Canadian Institutes of Health Research. Kerstin A. Klotz reports personal fees from GW Pharmaceuticals companies and Zogenix and was supported by the Berta-Ottenstein-Program for Clinician Scientists from the Faculty of Medicine, University of Freiburg. Gerhard Kluger reports personal fees from Desitin Arzneimittel, Eisai and Zogenix. Susanne Knake reports speaker's honoraria from Arvelle, Eisai, Epilog and UCB. Thomas Mayer reports personal fees and grants from Arvelle Therapeutics, Eisai, GW Pharmaceuticals companies, UCB and Zogenix. Sascha Meyer reports grants from Novartis, UCB, Shire, Deutsche Forschungsgemeinschaft and Epilepsiestiftung Dr. Wolf. Hiltrud Muhle reports personal fees from Desitin Arzneimittel, UCB, Novartis and Zogenix. Karen Müller-Schlüter reports personal fees from Nutricia, Desitin Arzneimittel, Shire, Medice, Novartis and UCB. Felix von Podewils reports personal fees and grants from Bial, Desitin Arzneimittel, Eisai, GW Pharmaceutical companies, Arvelle Therapeutics, Zogenix and UCB Pharma. Matthias Sauter reports personal fees from Novartis and GW Pharmaceuticals companies. Regina Trollmann reports personal fees from Eisai, Desitin, PTC Therapetics, Roche and Sanofi Genzyme. Adelheid Wiemer-Kruel reports personal fees from Desitin Arzneimittel, GW Pharmaceuticals companies, Nutricia GmbH, Vitaflo and UCB. Bernd Wilken reports fees and compensation for travel expenses from Eisai, Takeda/Shire, Ipsen and PharmAllergan. Adam Strzelczyk reports personal fees and grants from Arvelle Therapeutics, Desitin Arzneimittel, Eisai, GW Pharmaceuticals companies, LivaNova, Marinus Pharma, Medtronic, UCB and Zogenix. Ulrich Bettendorf, Janina Grau, Andreas Hahn, Hans Hartmann, Frauke Hornemann, Markus Knuf, Klaus Marquard, Susanne Ruf, Hannah Schäfer, Jan-Ulrich Schlump, Steffen Syrbe, Charlotte Thiels and Bianca Zukunft have no competing interests.

Ethics Approval This study received the approval of the local Ethics Committee of Goethe-University, Frankfurt am Main, Germany.

Consent to Participate Informed consent by the patient or legal guardian was mandatory to participate in this study.

Consent for Publication All participants in the study or their legal guardians consented to the publication of the collected data in an anonymised form when they were included in the study.

Availability of Data and Material Anonymised data will be made available on reasonable request, with respect to the German General Data Protection Regulation (Datenschutz-Grundverordnung, DGSVO).

Code Availability Not applicable.

Authors' Contributions LMW, FR, SSB, GKu and AS developed the idea for this analysis. LMW and AS conceived the paper, performed the statistical analysis and wrote the first draft. LMW, FR, SSB, GKu, JPZ, TB, AB, UB, DEF, JG, AH, HH, CH, FH, II, JJ, KMK, KAK, GKl, SK, MK, KM, TM, SM, HM, KMS, FvP, SR, MS, HS, JUS, SSy, CT, RT, AWK, BW, BZ and AS acquired patient data, edited the manuscript and discussed the results. LMW created the charts and figures. All authors contributed to the final manuscript, approved the final manuscript for publication and agree to be accountable for the work presented in the manuscript.

Open Access This article is licensed under a Creative Commons Attribution-NonCommercial 4.0 International License, which permits any non-commercial use, sharing, adaptation, distribution and reproduction in any medium or format, as long as you give appropriate credit to the original author(s) and the source, provide a link to the Creative
Commons licence, and indicate if changes were made. The images or other third party material in this article are included in the article's Creative Commons licence, unless indicated otherwise in a credit line to the material. If material is not included in the article's Creative Commons licence and your intended use is not permitted by statutory regulation or exceeds the permitted use, you will need to obtain permission directly from the copyright holder. To view a copy of this licence, visit http://creativecommons.org/licenses/by-nc/4.0/.

\section{References}

1. Zöllner JP, Franz DN, Hertzberg C, Nabbout R, Rosenow F, Sauter M, et al. A systematic review on the burden of illness in individuals with tuberous sclerosis complex (TSC). Orphanet J Rare Dis. 2020;15(1):23.

2. Strzelczyk A, Rosenow F, Zöllner JP, Simon A, Wyatt G, Holland $\mathrm{R}$, Schubert-Bast S. Epidemiology, healthcare resource use, and mortality in patients with tuberous sclerosis complex: a population-based study on German health insurance data. Seizure. 2021. https://doi.org/10.1016/j.seizure.2021.06.027.

3. Chu WC, Chiang LL, Chan DC, Wong WH, Chan GC. Prevalence, mortality and healthcare economic burden of tuberous sclerosis in Hong Kong: a population-based retrospective cohort study (1995-2018). Orphanet J Rare Dis. 2020;15(1):264.

4. Rosset C, Netto CBO, Ashton-Prolla P. TSC1 and TSC2 gene mutations and their implications for treatment in tuberous sclerosis complex: a review. Genet Mol Biol. 2017;40(1):69-79.

5. Sancak O, Nellist M, Goedbloed M, Elfferich P, Wouters C, MaatKievit A, et al. Mutational analysis of the TSC1 and TSC2 genes in a diagnostic setting: genotype-phenotype correlations and comparison of diagnostic DNA techniques in tuberous sclerosis complex. Eur J Hum Genet. 2005;13(6):731-41.

6. Maulaz P, Malinge MC, Farges D, Ingster O, Azzouzi AR, Bigot P. Prevalence of the tuberous sclerosis complex at patients taken care for a renal angiomyolipoma. Prog Urol. 2020;30(10):500-6.

7. Aw F, Goyer I, Raboisson MJ, Boutin C, Major P, Dahdah N. Accelerated cardiac rhabdomyoma regression with everolimus in infants with tuberous sclerosis complex. Pediatr Cardiol. 2017;38(2):394-400.

8. Arroyo MS, Krueger DA, Broomall E, Stevenson CB, Franz DN. Acute management of symptomatic subependymal giant cell astrocytoma with everolimus. Pediatr Neurol. 2017;72:81-5.

9. Randle SC. Tuberous sclerosis complex: a review. Pediatr Ann. 2017;46(4):e166-71.

10. Chu-Shore CJ, Major P, Camposano S, Muzykewicz D, Thiele EA. The natural history of epilepsy in tuberous sclerosis complex. Epilepsia. 2010;51(7):1236-41.

11. Capal JK, Bernardino-Cuesta B, Horn PS, Murray D, Byars AW, Bing NM, et al. Influence of seizures on early development in tuberous sclerosis complex. Epilepsy Behav. 2017;70(Pt A):245-52.

12. Schoenberger A, Capal JK, Ondracek A, Horn PS, Murray D, Byars AW, et al. Language predictors of autism spectrum disorder in young children with tuberous sclerosis complex. Epilepsy Behav. 2020;103(Pt A):106844.

13. Zöllner JP, Conradi N, Sauter M, Knuf M, Knake S, Kurlemann $\mathrm{G}$, et al. Quality of life and its predictors in adults with tuberous sclerosis complex (TSC): a multicentre cohort study from Germany. Neurol Res Pract. 2021;3(1):35.

14. Grau J, Zöllner JP, Schubert-Bast S, Kurlemann G, Hertzberg C, Wiemer-Kruel A, et al. Direct and indirect costs and cost-driving factors of Tuberous sclerosis complex in children adolescents 
and caregivers: a multicenter cohort study. Orphanet J Rare Dis. 2021;16(1):282.

15. Zöllner JP, Grau J, Rosenow F, Sauter M, Knuf M, Kurlemann G, et al. Direct and indirect costs and cost-driving factors in adults with tuberous sclerosis complex: a multicenter cohort study and a review of the literature. Orphanet J Rare Dis. 2021;16(1):250.

16. Santulli G, Totary-Jain H. Tailoring mTOR-based therapy: molecular evidence and clinical challenges. Pharmacogenomics. 2013;14(12):1517-26.

17. Franz DN, Belousova E, Sparagana S, Bebin EM, Frost MD, Kuperman R, et al. Long-term use of everolimus in patients with tuberous sclerosis complex: final results from the EXIST-1 study. PLoS ONE. 2016;11(6):e0158476.

18. Bissler JJ, Kingswood JC, Radzikowska E, Zonnenberg BA, Belousova E, Frost MD, et al. Everolimus long-term use in patients with tuberous sclerosis complex: four-year update of the EXIST-2 study. PLoS ONE. 2017;12(8):e0180939.

19. Franz DN, Lawson JA, Yapici Z, Ikeda H, Polster T, Nabbout $\mathrm{R}$, et al. Everolimus for treatment-refractory seizures in TSC: extension of a randomized controlled trial. Neurol Clin Pract. 2018;8(5):412-20.

20. Schubert-Bast S, Rosenow F, Klein KM, Reif PS, Kieslich M, Strzelczyk A. The role of mTOR inhibitors in preventing epileptogenesis in patients with TSC: current evidence and future perspectives. Epilepsy Behav. 2019;91:94-8.

21. Bevacqua M, Baldo F, Pastore S, Valencic E, Tommasini A, Maestro A, et al. Off-label use of sirolimus and everolimus in a pediatric center: a case series and review of the literature. Paediatr Drugs. 2019;21(3):185-93.

22. Willems L, Strzelczyk A, Rosenow F. Everolimus as diseasespecific treatment option in tuberous sclerosis complex-associated drug refractory epilepsy:a systematic review. Z Epileptol. 2021;34:168-74.

23. Northrup H, Krueger DA, International Tuberous Sclerosis Complex Consensus Group. Tuberous sclerosis complex diagnostic criteria update: recommendations of the 2012 Iinternational Tuberous Sclerosis Complex Consensus Conference. Pediatr Neurol. 2013;49(4):243-54.

24. von Elm E, Altman DG, Egger M, Pocock SJ, Gotzsche PC, Vandenbroucke JP, et al. The Strengthening the Reporting of Observational Studies in Epidemiology (STROBE) statement: guidelines for reporting observational studies. PLoS Med. 2007;4(10):e296.

25. Riechmann J, Strzelczyk A, Reese JP, Boor R, Stephani U, Langner C, et al. Costs of epilepsy and cost-driving factors in children, adolescents, and their caregivers in Germany. Epilepsia. 2015;56(9):1388-97.

26. Strzelczyk A, Nickolay T, Bauer S, Haag A, Knake S, Oertel WH, et al. Evaluation of health-care utilization among adult patients with epilepsy in Germany. Epilepsy Behav. 2012;23(4):451-7.

27. Strzelczyk A, Schubert-Bast S, Bast T, Bettendorf U, Fiedler B, Hamer HM, et al. A multicenter, matched case-control analysis comparing burden-of-illness in Dravet syndrome to refractory epilepsy and seizure remission in patients and caregivers in Germany. Epilepsia. 2019;60(8):1697-710.

28. Strzelczyk A, Kalski M, Bast T, Wiemer-Kruel A, Bettendorf U, Kay L, et al. Burden-of-illness and cost-driving factors in Dravet syndrome patients and carers: a prospective, multicenter study from Germany. Eur J Paediatr Neurol. 2019;23(3):392-403.

29. Privitera M, Ficker DM. Assessment of adverse events and quality of life in epilepsy: design of a new community-based trial. Epilepsy Behav. 2004;5(6):841-6.

30. Carreno M, Gil-Nagel A, Sanchez JC, Elices E, Serratosa JM, Salas-Puig J, et al. Strategies to detect adverse effects of antiepileptic drugs in clinical practice. Epilepsy Behav. 2008;13(1):178-83.
31. Rabin R, de Charro F. EQ-5D: a measure of health status from the EuroQol Group. Ann Med. 2001;33(5):337-43.

32. Ravens-Sieberer U, Bullinger M. Assessing health-related quality of life in chronically ill children with the German KINDL: first psychometric and content analytical results. Qual Life Res. 1998;7(5):399-407.

33. Riechmann J, Willems LM, Boor R, Kieslich M, Knake S, Langner C, et al. Quality of life and correlating factors in children adolescents with epilepsy and their caregivers: A cross-sectional multicenter study from Germany. Seizure. 2019;69:92-98.

34. Benjamini Y, Cohen R. Weighted false discovery rate controlling procedures for clinical trials. Biostatistics. 2017;18(1):91-104.

35. Benjamini Y, Hechtlinger Y. Discussion: an estimate of the science-wise false discovery rate and applications to top medical journals by Jager and Leek. Biostatistics. 2014;15(1):13-6.

36. Agostinelli A. Robust stepwise regression. J Appl Stat. 2002;29:825-40.

37. Zhan Y, Shen L, Xu W, Wu X, Zhang W, Wang J, et al. Functional improvements in patients with lymphangioleiomyomatosis after sirolimus: an observational study. Orphanet J Rare Dis. 2018;13(1):34.

38. Zhou L, Ouyang R, Luo H, Ren S, Chen P, Peng Y, et al. Efficacy of sirolimus for the prevention of recurrent pneumothorax in patients with lymphangioleiomyomatosis: a case series. Orphanet J Rare Dis. 2018;13(1):168.

39. McCormack FX, Inoue Y, Moss J, Singer LG, Strange C, Nakata $\mathrm{K}$, et al. Efficacy and safety of sirolimus in lymphangioleiomyomatosis. N Engl J Med. 2011;364(17):1595-606.

40. European Medicines Agency. EU/3/10/764: EMA statement on the use of everolimus in TSC; 2018.

41. Bissler J, Cappell K, Charles H, Song X, Liu Z, Prestifilippo J, et al. Long-term clinical morbidity in patients with renal angiomyolipoma associated with tuberous sclerosis complex. Urology. 2016;95:80-7.

42. Song X, Liu Z, Cappell K, Gregory C, Said Q, Prestifilippo J, et al. Natural history of patients with tuberous sclerosis complex related renal angiomyolipoma. Curr Med Res Opin. 2017;33(7):1277-82.

43. Tiberio D, Franz DN, Phillips JR. Regression of a cardiac rhabdomyoma in a patient receiving everolimus. Pediatrics. 2011;127(5):e1335-7.

44. Dhulipudi B, Bhakru S, Rajan S, Doraiswamy V, Koneti NR. Symptomatic improvement using everolimus in infants with cardiac rhabdomyoma. Ann Pediatr Cardiol. 2019;12(1):45-8.

45. Krueger DA, Capal JK, Curatolo P, Devinsky O, Ess K, Tzadok M, et al. Short-term safety of mTOR inhibitors in infants and very young children with tuberous sclerosis complex (TSC): multicentre clinical experience. Eur J Paediatr Neurol. 2018;22(6):1066-73.

46. Darling TN. Topical sirolimus to treat tuberous sclerosis complex (TSC). JAMA Dermatol. 2018;154(7):761-2.

47. Nathan N, Wang JA, Li S, Cowen EW, Haughey M, Moss J, et al. Improvement of tuberous sclerosis complex (TSC) skin tumors during long-term treatment with oral sirolimus. J Am Acad Dermatol. 2015;73(5):802-8.

48. Franz DN, Budde K, Kingswood JC, Belousova E, Sparagana $\mathrm{S}$, de Vries PJ, et al. Effect of everolimus on skin lesions in patients treated for subependymal giant cell astrocytoma and renal angiomyolipoma: final 4-year results from the randomized EXIST-1 and EXIST-2 studies. J Eur Acad Dermatol Venereol. 2018;32(10):1796-803.

49. Salussolia CL, Klonowska K, Kwiatkowski DJ, Sahin M. Genetic etiologies, diagnosis, and treatment of tuberous sclerosis complex. Annu Rev Genomics Hum Genet. 2019;31(20):217-40. 
50. Wiegand G, May TW, Ostertag P, Boor R, Stephani U, Franz DN. Everolimus in tuberous sclerosis patients with intractable epilepsy: a treatment option? Eur J Paediatr Neurol. 2013;17(6):631-8.

51. French JA, Lawson JA, Yapici Z, Ikeda H, Polster T, Nabbout $\mathrm{R}$, et al. Adjunctive everolimus therapy for treatment-resistant focal-onset seizures associated with tuberous sclerosis (EXIST-3): a phase 3, randomised, double-blind, placebo-controlled study. Lancet. 2016;388(10056):2153-63.

52. Krueger DA, Care MM, Agricola K, Tudor C, Mays M, Franz DN. Everolimus long-term safety and efficacy in subependymal giant cell astrocytoma. Neurology. 2013;80(6):574-80.

53. Samueli S, Abraham K, Dressler A, Groppel G, MuhlebnerFahrngruber A, Scholl T, et al. Efficacy and safety of everolimus in children with TSC-associated epilepsy: pilot data from an open single-center prospective study. Orphanet J Rare Dis. 2016;11(1):145.

54. Svarrer EMM, Fischer CM, Frederiksen MG, Born AP, HoeiHansen CE. Everolimus as adjunctive treatment in tuberous sclerosis complex-associated epilepsy in children. Dan Med J. 2019;66(12):A5582.

55. Kadish NE, Riedel C, Stephani U, Wiegand G. Developmental outcomes in children/adolescents and one adult with tuberous sclerosis complex (TSC) and refractory epilepsy treated with everolimus. Epilepsy Behav. 2020;111:107182.

56. Saffari A, Brosse I, Wiemer-Kruel A, Wilken B, Kreuzaler P, Hahn A, et al. Safety and efficacy of mTOR inhibitor treatment in patients with tuberous sclerosis complex under 2 years of age: a multicenter retrospective study. Orphanet J Rare Dis. 2019;14(1):96.

57. Mizuguchi M, Ikeda H, Kagitani-Shimono K, Yoshinaga H, Suzuki Y, Aoki M, et al. Everolimus for epilepsy and autism spectrum disorder in tuberous sclerosis complex: EXIST-3 substudy in Japan. Brain Dev. 2019;41(1):1-10.

58. Stockinger J, Strzelczyk A, Nemecek A, Cicanic M, Bösebeck F, Brandt C, et al. Everolimus in adult tuberous sclerosis complex patients with epilepsy: too late for success? A retrospective study. Epilepsia. 2021;62(3):785-94.

59. Curatolo P, Nabbout R, Lagae L, Aronica E, Ferreira JC, Feucht $\mathrm{M}$, et al. Management of epilepsy associated with tuberous sclerosis complex: updated clinical recommendations. Eur J Paediatr Neurol. 2018;22(5):738-48.

60. Strzelczyk A, Mann C, Willems LM, Rosenow F, Bauer S. Cenobamate for the treatment of focal epilepsies. Expert Opin Pharmacother. 2020;21(18):2215-23.

61. Strzelczyk A, Klein KM, Willems LM, Rosenow F, Bauer S. Brivaracetam in the treatment of focal and idiopathic generalized epilepsies and of status epilepticus. Expert Rev Clin Pharmacol. 2016;9(5):637-45.

62. Strzelczyk A, Steinig I, von Podewils F, Moddel G, Bauer S, Klein $\mathrm{KM}$, et al. Postmarketing experience with brivaracetam in the treatment of epilepsies: a multicentre cohort study from Germany. Epilepsia. 2017;58(7):1208-16.

63. Willems LM, Bauer S, Rosenow F, Strzelczyk A. Recent advances in the pharmacotherapy of epilepsy: brivaracetam and perampanel as broad-spectrum antiseizure drugs for the treatment of epilepsies and status epilepticus. Expert Opin Pharmacother. 2019;20(14):1755-65

64. Willems LM, Bertsche A, Bosebeck F, Hornemann F, Immisch I, Klein KM, et al. Efficacy, retention, and tolerability of brivaracetam in patients with epileptic encephalopathies: a multicenter cohort study from Germany. Front Neurol. 2018;9:569.

65. Strzelczyk A, Willems LM, Willig S, Rosenow F, Bauer S. Perampanel in the treatment of focal and idiopathic generalized epilepsies and of status epilepticus. Expert Rev Clin Pharmacol. 2015;8(6):733-40.
66. Willems LM, Zöllner JP, Paule E, Schubert-Bast S, Rosenow F, Strzelczyk A. Eslicarbazepine acetate in epilepsies with focal and secondary generalised seizures: systematic review of current evidence. Expert Rev Clin Pharmacol. 2018;11(3):309-24.

67. Menzler K, Mross PM, Rosenow F, Schubert-Bast S, Willems LM, Zahnert F, et al. First clinical postmarketing experiences in the treatment of epilepsies with brivaracetam: a retrospective observational multicentre study. BMJ Open 2019;9(11):e030746.

68. Schubert-Bast S, Willems LM, Kurlemann G, Knake S, MüllerSchlüter K, Rosenow F, Strzelczyk A. Postmarketing experience with brivaracetam in the treatment of focal epilepsy in children and adolescents. Epilepsy Behav. 2018;89:89-93.

69. Strzelczyk A, Kay L, Bauer S, Immisch I, Klein KM, Knake S, et al. Use of brivaracetam in genetic generalized epilepsies and for acute intravenous treatment of absence status epilepticus. Epilepsia. 2018;59(8):1549-1556.

70. Löscher W, Klein P. The Pharmacology and Clinical Efficacy of Antiseizure Medications: From Bromide Salts to Cenobamate and Beyond. CNS Drugs. 2021. https://doi.org/10.1007/ s40263-021-00827-8.

71. Cappellano AM, Senerchia AA, Adolfo F, Paiva PM, Pinho R, Covic A, et al. Successful everolimus therapy for SEGA in pediatric patients with tuberous sclerosis complex. Childs Nerv Syst. 2013;29(12):2301-5.

72. Curran MP. Everolimus: in patients with subependymal giant cell astrocytoma associated with tuberous sclerosis complex. Paediatr Drugs. 2012;14(1):51-60.

73. Franz DN, Agricola K, Mays M, Tudor C, Care MM, HollandBouley K, et al. Everolimus for subependymal giant cell astrocytoma: 5-year final analysis. Ann Neurol. 2015;78(6):929-38.

74. Hatano T, Endo K, Tamari M. Efficacy and safety of low-dose everolimus treatment for renal angiomyolipoma associated with tuberous sclerosis complex. Int J Clin Oncol. 2021;26(1):163-8.

75. Dahdah N. Everolimus for the treatment of tuberous sclerosis complex-related cardiac rhabdomyomas in pediatric patients. $\mathbf{J}$ Pediatr. 2017;190:21-6.e7.

76. Martinez-Garcia A, Michel-Macias C, Cordero-Gonzalez G, Escamilla-Sanchez KI, Aguinaga-Rios M, Coronado-Zarco A, et al. Giant left ventricular rhabdomyoma treated successfully with everolimus: case report and review of literature. Cardiol Young. 2018;28(7):903-9.

77. Wahid S, Chiang PC, Luo HL, Huang SC, Tsai EM, Chiang PH. Pelvic lymphangioleiomyomatosis treated successfully with everolimus: two case reports with literature review. Medicine (Baltimore). 2017;96(10):e4562.

78. Germain N, Aballea S, Toumi M. Measuring the health-related quality of life in young children: how far have we come? J Mark Access Health Policy. 2019;7(1):1618661.

79. Pavel ME, Singh S, Strosberg JR, Bubuteishvili-Pacaud L, Degtyarev E, Neary MP, et al. Health-related quality of life for everolimus versus placebo in patients with advanced, nonfunctional, well-differentiated gastrointestinal or lung neuroendocrine tumours (RADIANT-4): a multicentre, randomised, double-blind, placebo-controlled, phase 3 trial. Lancet Oncol. 2017;18(10):1411-22.

80. Davies M, Saxena A, Kingswood JC. Management of everolimusassociated adverse events in patients with tuberous sclerosis complex: a practical guide. Orphanet J Rare Dis. 2017;12(1):35.

81. Jozwiak S, Kotulska K, Berkowitz N, Brechenmacher T, Franz DN. Safety of everolimus in patients younger than 3 years of age: results from EXIST-1, a randomized, controlled clinical trial. J Pediatr. 2016;172:151-5.e1. 
82. Hawcutt DB, Russell NJ, Maqsood H, Kouranloo K, Gomberg $\mathrm{S}$, Waitt $\mathrm{C}$, et al. Spontaneous adverse drug reaction reports for neonates and infants in the UK 2001-2010: content and utility analysis. Br J Clin Pharmacol. 2016;82(6):1601-12.

83. Bach VA, Neininger MP, Spindler UP, Hotopp LC, Hornemann F, Syrbe S, et al. How do parents perceive adverse drug events of their children's anticonvulsant medication? Eur J Paediatr Neurol. 2018;22(3):427-33.

84. Dubrall D, Schmid M, Alesik E, Paeschke N, Stingl J, Sachs B. Frequent adverse drug reactions, and medication groups under suspicion. Dtsch Arztebl Int. 2018;115(23):393-400.
85. Kwon OY, Park SP. Validity of the Liverpool Adverse Events Profile as a screening tool for detecting comorbid depression or anxiety disorder in people with epilepsy. J Epilepsy Res. 2018;8(2):74-80.

86. Sanchez-Fructuoso AI, Ruiz JC, Perez-Flores I, Gomez Alamillo C, Calvo Romero N, Arias M. Comparative analysis of adverse events requiring suspension of mTOR inhibitors: everolimus versus sirolimus. Transplant Proc. 2010;42(8):3050-2.

87. Sedgwick P. Questionnaire surveys: sources of bias. BMJ. 2013;30:347.

\section{Authors and Affiliations}

Laurent M. Willems ${ }^{1,2} \cdot$ Felix Rosenow $^{1,2} \cdot$ Susanne Schubert-Bast ${ }^{1,2,3} \cdot$ Gerhard Kurlemann $^{4}$. Johann Philipp Zöllner ${ }^{1,2}$. Thomas Bast ${ }^{5}$. Astrid Bertsche ${ }^{6}$. Ulrich Bettendorf ${ }^{7}$. Daniel Ebrahimi-Fakhari ${ }^{8}$. Janina Grau ${ }^{1,2}$. Andreas Hahn ${ }^{9}$. Hans Hartmann ${ }^{10}$. Christoph Hertzberg ${ }^{11}$. Frauke Hornemann ${ }^{12} \cdot$ Ilka Immisch $^{13}$. Julia Jacobs ${ }^{14,15}$. Karl Martin Klein ${ }^{12,16} \cdot$ Kerstin A. Klotz ${ }^{14,17}$. Gerhard Kluger ${ }^{18,19}$. Susanne Knake ${ }^{13}$. Markus Knuf ${ }^{20,21}$ - Klaus Marquard ${ }^{22}$ - Thomas Mayer ${ }^{23}$ - Sascha Meyer ${ }^{24} \cdot$ Hiltrud Muhle $^{25} \cdot$ Karen Müller-Schlüter $^{26}$. Felix von Podewils ${ }^{27}$. Susanne Ruf ${ }^{28}$. Matthias Sauter ${ }^{29} \cdot$ Hannah Schäfer $^{30,31}$. Jan-Ulrich Schlump ${ }^{32}$. Steffen Syrbe ${ }^{33} \cdot$ Charlotte Thiels $^{34} \cdot$ Regina Trollmann $^{35} \cdot$ Adelheid Wiemer-Kruel $^{5} \cdot$ Bernd Wilken $^{36}$. Bianca Zukunft ${ }^{37} \cdot$ Adam Strzelczyk $^{1,2,13}$ (1)

Adam Strzelczyk

strzelczyk@med.uni-frankfurt.de

1 Epilepsy Center Frankfurt Rhine-Main and Department of Neurology, Goethe-University Frankfurt, Schleusenweg 2-16 (Haus 95), 60528 Frankfurt am Main, Germany

2 LOEWE Center for Personalized Translational Epilepsy Research (CePTER), Goethe-University Frankfurt, Frankfurt am Main, Germany

3 Department of Neuropediatrics, Goethe-University Frankfurt, Frankfurt am Main, Germany

4 St. Bonifatius Hospital, Lingen, Germany

5 Epilepsy Center Kork, Clinic for Children and Adolescents, Kehl-Kork, Germany

6 Department of Neuropediatrics, University Hospital for Children and Adolescents, Rostock, Germany

7 Neuropediatric Practice, Hirschaid, Germany

8 Department of General Pediatrics, Division of Neuropediatrics, University Hospital Münster, Münster, Germany

9 Department of Neuropediatrics, Justus-Liebig-University Gießen, Gießen, Germany

10 Clinic for Pediatric Kidney, Liver and Metabolic Diseases, Hannover Medical School, Hannover, Germany

11 Department of Neuropediatrics, Vivantes Klinikum Neukölln, Berlin, Germany

12 Department of Neuropediatrics, Leipzig University Hospital for Children and Adolescents, Leipzig, Germany

13 Epilepsy Center Hessen and Department of Neurology, Philipps-University Marburg, Marburg (Lahn), Germany
14 Department of Neuropediatrics and Muscle Disorders, Center for Pediatrics, Faculty of Medicine, University of Freiburg, Freiburg im Breisgau, Germany

15 Department of Pediatrics and Clinical Neurosciences, Cumming School of Medicine, University of Calgary, Calgary, AB, Canada

16 Departments of Clinical Neurosciences, Medical Genetics and Community Health Sciences, Hotchkiss Brain Institute and Alberta Children's Hospital Research Institute, Cumming School of Medicine, University of Calgary, Calgary, AB, Canada

17 Berta-Ottenstein-Programme, Faculty of Medicine, University of Freiburg, Freiburg im Breisgau, Germany

18 Clinic for Neuropediatrics and Neurorehabilitation, Epilepsy Center for Children and Adolescents, Schön Klinik Vogtareuth, Vogtareuth, Germany

19 Research Institute, Rehabilitation, Transition and Palliation, PMU Salzburg, Salzburg, Austria

20 Department of Pediatrics, Klinikum Worms, Worms, Germany

21 Department of Pediatrics, University Medicine Mainz, Mainz, Germany

22 Department of Pediatric Neurology, Psychosomatics and Pain Management, Klinikum Stuttgart, Stuttgart, Germany

23 Epilepsy Center Kleinwachau, Radeberg, Germany

24 Department of Neuropediatrics, University Children's Hospital of Saarland, Homburg, Germany

25 Department of Neuropediatrics, Christian-Albrechts-University Kiel and University Hospital Schleswig-Holstein, Kiel, Germany 
26 Epilepsy Center for Children, University Hospital Neuruppin, Brandenburg Medical School, Neuruppin, Germany

27 Department of Neurology, Epilepsy Center, University Medicine Greifswald, Greifswald, Germany

28

Department of Neuropediatrics, University Hospital Tübingen, Tübingen, Germany

29 Klinikum Kempten, Klinikverbund Allgäu, Kempten/Allgäu, Germany

30 Division of Nephrology, Medizinische Klinik und Poliklinik IV, Klinikum der LMU München - Innenstadt, München, Germany

31 Department of Nephrology, Klinikum rechts der Isar, Technische Universität München, Munich, Germany

32 Department of Neuropediatrics, University of Witten/Herdecke, Herdecke, Germany
33 Division of Pediatric Epileptology, Center for Pediatrics and Adolescent Medicine, University Hospital Heidelberg, Heidelberg, Germany

34 Department of Neuropediatrics and Social Pediatrics, St. Josef-Hospital, University Hospital of Pediatrics and Adolescent Medicine, Ruhr-University Bochum, Bochum, Germany

35 Department of Neuropediatrics, Friedrich-Alexander University of Erlangen-Nürnberg, Erlangen, Germany

36 Department of Neuropediatrics, Klinikum Kassel, Kassel, Germany

37 Department of Nephrology and Internal Intensive Care, Charité - University Medicine Berlin, Berlin, Germany 